\title{
Airborne Fungi in Neonatal Intensive Care Unit of a Public Hospital in Brazil
}

\author{
Aryanna Kelly Pinheiro Souza ${ }^{1}$, Jean Phellipe Marques do Nascimento ${ }^{2}$, \\ Maria Anilda dos Santos Araújo ${ }^{1}$, Krystianelly Patrícia da Silva Pedrosa ${ }^{2}$, \\ Bruno Mendes Tenorio ${ }^{3}$, Luana Luzia Santos Pires ${ }^{2}$, Gabryelle Barbosa Cordeiro de \\ Lima $^{2}$, Rebeca Ingrid dos Santos Barboza ${ }^{2}$ and Eurípedes Alves da Silva Filho ${ }^{2 *}$ \\ ${ }^{1}$ Superior Studies Center of Maceió (CESMAC), Maceió, Alagoas, Brazil \\ ${ }^{2}$ Laboratory of Climatized Environments, Institute of Biological and Health Sciences, Federal \\ University of Alagoas, Maceió, Alagoas, Brazil \\ ${ }^{3}$ Laboratory of Histology and Embryology, Institute of Biological and Health Sciences, \\ Federal University of Alagoas, Maceió, Alagoas, Brazil \\ *Corresponding author
}

Keywords

Air quality, Airborne fungi,

Neonatal ICU, Hospital infection, Indoor air

Article Info

Accepted:

10 November 2019 Available Online: 10 December 2019
Fungi are opportunistic organisms with wide geographical distribution and can also be found in the hospital environment. These microorganisms can cause infections, especially in immunocompromised patients. The aim of this study was to evaluate airborne fungal contamination in two neonatal intensive care units (ICU) of a public hospital before and after cleaning. The technique of Petri dishes exposure containing Sabouraud agar with $50 \mathrm{mg} / \mathrm{L}$ chloramphenicol was used for sample collection. Air conditioning filters were also sampled using a sterile swab for fungal collection. The identification of fungal isolates was performed by observing macroscopic and microscopic structures. A total of 1305 colony forming units was isolated, where: $718(55.0 \%)$ were isolated before neonatal ICU cleaning and $587(45.0 \%)$ after cleaning. Forty-two species belonging to 24 genera were identified, being Cladosporium cladosporioides, Penicillium aurantiogriseum and Aspergillus oryzae the most frequent species in the analyzed samples. The presence of pathogenic fungi in ICUs demonstrates the need for constant monitoring of indoor air quality in order to better control airborne contamination in hospital environments. 


\section{Introduction}

The fungi spread through the atmospheric air are called airborne fungi and by being opportunistic they can cause humans diseases. The airborne fungi are related to human health, mainly by the potential to trigger allergic processes, irritation of mucous membranes and skin and fungal infections in people sensitive to their seedlings and toxigenic metabolites (Baxi et al., 2016; Setlhare et al., 2014).

Opportunistic fungi such those from the genera Penicillium, Aspergillus, Cladosporium, Fusarium and Candida are responsible for diseases ranging from ear infections, cutaneous infections, mycotoxicosis, urinary infections, pneumonia, onychomycosis, eye infections until fungemias (Nascimento et al., 2019).

Hospital environment often has microorganisms in the air, floor, walls, surgical equipment, hospital furniture, refrigeration systems and employees, preferentially infecting immunocompromised patients who use catheters and dialysis, as well as newborns and elderly, causing severe intrahospital infections (Cristina et al., 2009; Setlhare et al., 2014). Therefore, indoor air quality procedures in hospital environments are critical factors in preventing infections (Azimi et al., 2013).

Hospital infections are an important factor for increased neonatal mortality. Literature data show that mortality in this age range is between 15.5 and $64.4 \%$ in cases related to nosocomial infection (NI).

Infections in newborns are always considered from hospital, except for those transmitted via placenta and those associated with premature rupture of membranes for more than 24 hours (Duarte and Mendonça, 2005). The first reports about the importance of the hospital environment as a transmission source of infectious agents associated with air pollution analyzed the spores of Aspergillus sp, thus, exposure to air contaminated by fungi and its metabolites in indoor air-conditioned have worried the scientific and health community around the world (Boff et al., 2013).

Due to the pathogenic potential of airborne fungi, especially in neonates cared in hospital air-conditioned environments (Cristina et al., 2009), the aim of this study was to evaluate airborne fungal contamination in two neonatal intensive care units (ICU) of a public hospital before and after cleaning.

\section{Material and Methods}

\section{Site and collection technique}

Air samples were collected from two sites (A and $\mathrm{B}$ ) of climatized neonatal intensive care unit at the university hospital. Dr. Alberto Antunes located in the city of Maceió, Alagoas, Brazil.

Fungi collection from the air was performed by passive sedimentation through Petri dishes exposure containing Sabouraud agar plus 50 $\mathrm{mg} / \mathrm{L}$ chloramphenicol for deposition of fungal propagules present in atmospheric air according to Napoli et al., (2012). Disposable Petri dishes were opened in both environments during 20 minutes at a height of one meter from the floor. Before and after cleaning, 10 plates were exposed to the environment $A$ and 10 plates in the environment $\mathrm{B}$, totaling 400 exposures during the study.

Sample collection from the air conditioner filters was performed using a sterile swab moistened with sterile water plus $50 \mathrm{mg} / \mathrm{L}$ chloramphenicol, subsequently seeded by radial spreading into a disposable Petri dish containing the medium described above. 


\section{Fungi Identification}

Filamentous fungi identification was based on macroscopic aspects of colonies and microscopic characteristics by direct examination of the culture according to Hoog et al., (2000). Those which could not be identified by the absence of reproductive structures were grown in special medium to stimulate sporulation, using the in-slides microculture technique according to Ridel (1950). After identification, isolates were preserved under mineral oil according to Sherf (1943).

\section{Statistical analysis}

Results were analyzed in the software Biostat ${ }^{\circledR}$ 5.0 using the paired Anova-Manova, $t$-test and z-test applied to assess the variables found before and after the neonatal ICU hygiene. A p- value $<0.05$ was considered statistically significant.

\section{Results and Discussion}

Quantitative results of airborne fungi isolated from Neonatal ICU before and after cleaning are shown in Table 1. Analysis of colonies showed the presence of total 1305 colony forming units (CFU); $718 \mathrm{CFU}$ (55.0\%) of these were isolated before cleaning and 587 CFU (45.0\%) after cleaning the neonatal ICU. The total average values of colonies found in each sample before and after cleaning were $8.23 \pm 7.39$ and $11.19 \pm 10.34 \mathrm{CFU}$, respectively.

Overall, $772 \mathrm{CFU}$ were isolated in the environment $\mathrm{A}$, being $400 \mathrm{CFU}$ before and 372 after cleaning, with average value of 9.07 $\pm 12.04 \mathrm{CFU}$ and $7.93 \pm 12.95 \mathrm{CFU}$ respectively, with no reduction in fungi concentration after cleaning (Figure 1). In environment $\mathrm{B}$ were isolated $533 \mathrm{CFU}$, being $318 \mathrm{CFU}$ obtained before and $215 \mathrm{CFU}$ after cleaning, with average of $7.38 \pm 10.34 \mathrm{CFU}$ and $5.10 \pm 7.96$ respectively (Figure 1 ). It was observed a statistically significant reduction in $\mathrm{CFU}$ values after cleaning only in the environment B.

Table 1 shows the identification of pathogenic, toxigenic and allergenic fungi in both environments (A and $\mathrm{B}$ ) from the neonatal ICU. During this study, 42 species in 24 genera were identified according to the classification system of Alexopoulos (1996), in the class of Deuteromycetes, subclass Hyphomycetidae, including two families Moniliaceae and Dematiaceae.

Among the genera isolated, Cladosporium was the most frequent with 324 (26.8\%) CFU, followed by Penicillium with 300 CFU (24.8\%) and Aspergillus with 257 (21.3\%); in addition, other genera showed frequencies less than $4.7 \%$ of total colonies isolated. The most frequent species observed in this study were C. cladosporioides (186 CFU, 15.4\%), followed by $P$. aurantiogriseum (132 UFC, $10.9 \%$ ) and $A$. oryzae (113 CFU, 9.3\%). According to fungi characteristics, $27(65.8 \%)$ are considered pathogenic, 9 (21.9\%) nonpathogenic, $4(9.8 \%)$ allergenic and $1(2.5 \%)$ toxigenic. All species from the genus Aspergillus found in both neonatal ICU environments are pathogenic and among them, A. oryzae and A. fumigatus are also allergenic. Among Penicillium species, only $P$. aurantiogriseum and $P$. verruculosum were not reported as pathogenic to man.

A total of $59 \mathrm{CFU}$ of yeasts were isolated from the air at the neonatal ICU, $26 \mathrm{CFU}$ (44.1\%) from the environment $\mathrm{A}$ and $33 \mathrm{CFU}$ (55.9\%) from the environment $\mathrm{B}$ (Table 1). There was no significant $\mathrm{CFU}$ reduction after the environment cleanup. Among the yeasts, the species Candida parapsilosis was the most frequent with $35 \mathrm{CFU}$ (59.3\%), followed by $C$. guilliermondii with 11 CFU (18.6\%), $C$. 
albicans with $7 \mathrm{CFU}$ (11.8\%), C. tropicalis with 3 UFC (5.1\%). Three unidentified yeasts do not amplified with the species-specific primers used.

The airborne fungi analysis before and after cleaning the environments $\mathrm{A}$ and $\mathrm{B}$ showed CFU reduction for the genus Cladosporium. However, the numbers of CFU from the genera Aspergillus and Penicillium obtained before cleaning were lower than those observed after cleanup completion, observing a significant increase $(p<0.05)$ of these genera (Figure 2).

Figure 3 shows the fungi species isolated from the air conditioner filters. The species Cladosporium cladosporioides was isolated in almost $80 \%$ of cases, followed by $C$. herbarum with $30 \%$. It is also noteworthy: C. sphaerospermum and $P$. aurantiogriseum both with about $20 \%$ (Figure 3 ).

Results of this work and other studies such those developed by Setlhare et al., (2014) and Cabo Verde et al., (2015) in hospital environments show the diversity of fungi capable of developing allergic reactions and sensitization of atopic individuals as well as fungal infections of diverse etiologies. This factor roborates with the indoors airborne fungi researches monitoring.

The presence of pathogenic fungi is associated with various diseases, among them the aspergillosis; determining specific pathological conditions, especially in immunocompromised patients, neonates and children (Cristina et al., 2009). Furthermore, fungi contamination of the indoor atmosphere may influence the occurrence of invasive aspergillosis in intensive care units (Boff et al., 2013). The isolation of several Aspergillus species previously described as pathogenic in this study suggests the possibility of development of various symptoms that can lead to illness, absenteeism of employees, as well as emerging risk to patients in the ICU. The well-performed cleaning and disinfection in hospitals are effective measures of prevention and extinction of the epidemiological chain of infections (Gebel $e t$ al., 2013). However, the cleaning improperly performed cannot eliminate the microorganisms and move the microbial load from one location to another (Vikke and Giebner, 2016). In this sense, it is of concern the number of fungi $\mathrm{CFU}$ that increased or remained in the environment $\mathrm{A}$, even after cleaning since fungi are used as epidemiological markers for monitoring of artificially air-conditioned environment by national and international health monitoring agencies.

One of the reasons for not reducing the $\mathrm{CFU}$ quantity in the environment A may be the fact that cleaning first occurs in the environment $\mathrm{B}$, thus allowing the passage of fungal spores by scanning and re-using of rags and little concentrated solutions which did not eliminate microorganisms. The increased number of CFU after the hygiene for fungi from the genera Aspergillus and Penicillium can be justified by the high sporulation produced by these fungi and the inadequate hygiene that allows spores suspension in the environment air. These results support the need of changes in the management of some hospital services to introduce improvements in procedures and technologies of cleaning activity, hygiene and monitoring of hospital air-conditioned environments.

Studies developed by Tong et al., (2017) and Gonçalves et al., (2017) on fungal dispersion and hospital environments indicated that events of disinfection, ventilation and personnel transit are determining factors for the presence of anemophilus fungi in the environment. Of all factors, human presence contributes significantly to the fungal diversity observed in indoor air in hospitals. The Cladosporium and Penicillium genus are 
among the most reported in the literature as air contaminants in hospital environments and our results have corroborated with results from previous studies. (Sepahvand et al., 2017). According to Lobato et al., (2009) the seasonality and prevalence of airborne fungi in a hospital in southern Rio Grande do Sul Brazil showed a higher frequency of Cladosporium, Aspergillus and Alternaria. However, Rostami et al., (2017) showed the presence of the Yeast species, Penicillium and Aspergillusas being fungi more prevalent in various sectors of an Educational, Research and Treatment Center.

High microbial counts were found in a hospital in the Free State province - South Africa, the genera of fungi identified included Candida, Aureobasidium, Phoma and Penicillium. Some of these microorganisms can cause food spoilage and human diseases, especially in immunocompromised patients (Setlhare et al., 2014). Total mean concentration fungi in the hospital rooms in Tehran - Iran was $55 \mathrm{CFU} / \mathrm{m}^{3}$, these concentrations showed different levels of contamination with the highest $97 \mathrm{CFU} / \mathrm{m}^{3}$ observed in Orthopedics Operating Room. The most common fungi were Penicillium (70\%), Aspergillus (14\%), Cladosporium (12\%) and Alternaria (2\%) (Azimi et al., 2013).

Analyzes carried out by Okten and Asan (2012) in the indoor and outdoor atmosphere of the Pediatric Unit in a Hospital in Edirne Turkey showed 65 species of fungi from 16 genera, the most frequent genus was Cladosporium (33.58\%), Alternaria (22.53\%) and Penicillium (20.35\%). The most prevalent airborne fungi contaminating intensive care units and operation rooms in Assiut Hospitals - Egypt were Cladosporium, Aspergillus, Penicillium and Fusarium (Aboul-Nasr et al.,
2014). A study in Davanagere - India showed the presence of Aspergillus spp, Curvularia spp, Alternaria spp, Penicillium spp, Rhizopus spp, Nigrospora spp and Fusariumspp in health care centers (Rangaswamy et al., 2013.

In this study, Aspergillus spp was dominant in the Government health care center and Alternaria spp and Curvularia spp were dominant in the private health care center.

Indoor fungal characterization at different hospital sites in Setúbal - Portugal showed the prevalence of genera Penicillium (41\%), Aspergillus (24\%) and Cladosporium (14\%) (Cabo Verde et al., 2015). On the other hand, Rocha et al., (2012) observed that most of the public hospital sites in Caracas, showed fungal densities values within the "very clean" or "clean" standards. These authors also showed the isolation of 12 genera and 5 species, including Aspegillus and Penicillum spp. as the most frequent fungi. Chang et al., (2015) also reported that the fungal concentrations for different locations in Intensive Care Unit in Taiwan did not reach statistical significance and generally were in the standards.

Whereas the Neonates in intensive care units are classified as high-risk patients (Cristina et al., 2009), fungi is widely variable in its incidence; according to the season, temperature, relative humidity, time of day, speed and wind direction, presence of human activity and environment climate (Nevalainen et al.,, 2015). Rangaswamy et al., (2013) also reported considerable difference in the number of fungi in the morning and in the evening. Studies by Lugauskas and Kriskstaporis (2004) in hospitals and medical institutions of Lithuania showed the species Cladosporium cladosporioides as most frequent isolate, a similar result found in the present study. 
Table.1 Airborne fungi isolated from the two environments (A and B) before and after cleaning in the University Hospital Prof. Alberto Antunes HUPAA/Maceio, Alagoas, Brazil

\begin{tabular}{|c|c|c|c|c|c|c|c|c|c|}
\hline \multirow[t]{3}{*}{ SPECIES } & \multicolumn{4}{|c|}{$\begin{array}{l}\text { NEONATAL ICU } \\
\text { ENVIRONMENT A }\end{array}$} & \multicolumn{4}{|c|}{$\begin{array}{l}\text { NEONATAL ICU } \\
\text { ENVIRONMENT B }\end{array}$} & \multirow{3}{*}{ TOTAL } \\
\hline & \multicolumn{2}{|c|}{$\begin{array}{l}\text { Before } \\
\text { cleaning }\end{array}$} & \multicolumn{2}{|c|}{$\begin{array}{l}\text { After } \\
\text { cleaning }\end{array}$} & \multicolumn{2}{|c|}{$\begin{array}{l}\text { Before } \\
\text { cleaning }\end{array}$} & \multicolumn{2}{|c|}{$\begin{array}{c}\text { After } \\
\text { Cleaning }\end{array}$} & \\
\hline & UFC & $\%$ & UFC & $\%$ & UFC & $\%$ & UFC & $\%$ & \\
\hline Aspergillus fumigatus $\mathbf{P} ; \mathbf{A}$ & 8 & 19,5 & 15 & 36,6 & 8 & 19,5 & 10 & 24,4 & 41 \\
\hline A. nidulans $^{\mathbf{P}}$ & 7 & 29,2 & 10 & 41,7 & 4 & 16,6 & 3 & 12,5 & 24 \\
\hline A. niger $^{\mathbf{P}}$ & 11 & 18,3 & 19 & 31,6 & 12 & 20,1 & 18 & 30,0 & 60 \\
\hline A. ustus $^{\mathbf{P}}$ & 5 & 26,3 & 7 & 36,8 & 5 & 26,4 & 2 & 10,5 & 19 \\
\hline A. oryzae $\mathbf{P}^{\mathbf{P} \mathbf{A}}$ & 26 & 23,0 & 38 & 33,6 & 16 & 14,2 & 33 & 29,2 & 113 \\
\hline Acremonium kiliense ${ }^{\mathbf{P}}$ & 5 & 100 & - & - & - & - & - & - & 5 \\
\hline Alternaria alternata $^{\mathbf{P}}$ & 8 & 80 & 2 & 20 & - & & - & & 10 \\
\hline Aureobasidium pullulans ${ }^{\mathbf{P}}$ & 11 & 22,0 & 9 & 18,0 & 22 & 44,0 & 8 & 16,0 & 50 \\
\hline Bipolaris spicifera $^{\mathbf{P}}$ & 2 & 100 & - & - & - & - & - & - & 2 \\
\hline B. hawaiiensis ${ }^{\mathbf{P}}$ & 2 & 66,7 & 1 & 33,3 & - & - & - & - & 3 \\
\hline Candida albicans $^{\mathbf{P}}$ & 4 & 57,1 & 1 & 14,3 & 2 & 28,6 & - & - & 7 \\
\hline C. guilliermondii $^{\mathbf{P}}$ & 5 & 45,4 & 2 & 18,2 & 3 & 27,3 & 1 & 9,1 & 11 \\
\hline C. parapsilosis $^{\mathbf{P}}$ & 12 & 34,3 & 8 & 22,8 & 10 & 28,6 & 5 & 14,3 & 35 \\
\hline C. tropicalis $^{\mathbf{P}}$ & 3 & 100 & - & & - & & - & - & 3 \\
\hline Chaetomium globosum $^{\mathbf{P} ; \mathbf{A}}$ & 4 & 57,1 & - & - & 3 & 42,9 & - & - & 7 \\
\hline Cladosporium cladosporioides $\mathbf{N P}$ & 64 & 34,4 & 52 & 27,9 & 48 & 25,8 & 22 & 11,8 & 186 \\
\hline C. herbarum $^{\mathrm{P}}$ & 18 & 56,2 & 5 & 15,6 & 9 & 28,1 & - & - & 32 \\
\hline C. oxysporum ${ }^{\mathbf{P}}$ & 2 & 16,7 & - & - & 6 & 50 & 4 & 33,3 & 12 \\
\hline C. sphaerospermum ${ }^{\mathbf{P}}$ & 24 & 25,5 & 11 & 11,7 & 36 & 38,3 & 23 & 24,4 & 94 \\
\hline Curvularia giniculata $^{\mathbf{P}}$ & - & - & - & - & 5 & 62,5 & 3 & 37,5 & 8 \\
\hline C. lunata $^{\mathbf{P}}$ & 4 & 66,7 & 2 & 33,3 & - & - & - & - & 6 \\
\hline C. clavata $^{\mathbf{P}}$ & 5 & 41,7 & 3 & 25,0 & 4 & 33,3 & - & & 12 \\
\hline Fusarium incarnatum $^{\mathbf{P}}$ & 3 & 75,0 & - & - & 1 & 25,0 & - & - & 4 \\
\hline$F$. subglutinans ${ }^{\mathbf{P}}$ & 2 & 66,7 & 1 & 33,3 & - & - & - & - & 3 \\
\hline Geotrichum candidum $^{\mathbf{P} ; \mathbf{T}}$ & 19 & 57,5 & 9 & 27,2 & 4 & 12,2 & 1 & 3,1 & 33 \\
\hline Gliocladium roseum $^{\mathbf{N P}}$ & 6 & 66,7 & 2 & 22,3 & 1 & 11,0 & - & - & 9 \\
\hline Hortaea werneckii $^{\mathbf{P}}$ & 1 & 100 & - & - & - & & - & - & 1 \\
\hline Monilia sitophila $^{\mathbf{N P}}$ & 16 & 30,2 & 12 & 22,6 & 17 & 32,1 & 8 & 15,1 & 53 \\
\hline Mycelia sterilia $^{\mathbf{N P}}$ & 23 & 40,3 & 15 & 26,3 & 14 & 24,5 & 5 & 8,9 & 57 \\
\hline Nigrospora sphaerica $^{\mathrm{NP}}$ & - & - & - & - & 1 & 100 & - & - & 1 \\
\hline Penicillium aurantiogriseum ${ }^{\mathrm{NP}}$ & 38 & 28,8 & 56 & 42,4 & 17 & 12,9 & 21 & 15,9 & 132 \\
\hline P. chysogenum $^{\mathbf{P}}$ & 7 & 19,5 & 12 & 33,3 & 7 & 19,4 & 10 & 27,8 & 36 \\
\hline P. citrinum $^{\mathbf{P}}$ & 1 & 8,3 & 5 & 41,7 & 2 & 16,6 & 4 & 33,4 & 12 \\
\hline P. decubens $\mathbf{P}$ & - & - & - & - & 5 & 62,5 & 3 & 37,5 & 8 \\
\hline P. expansum $^{\mathbf{P}}$ & 10 & 14,7 & 16 & 23,5 & 28 & 41,2 & 14 & 20,6 & 68 \\
\hline P. purpurogenum $\mathbf{P ; \mathbf { A }}$ & 4 & 25 & 6 & 37,5 & 4 & 25 & 6 & 37,5 & 16 \\
\hline P. verruculosum ${ }^{\mathrm{NP}}$ & 5 & 17,8 & 9 & 32,1 & 5 & 17,8 & 9 & 32,1 & 28 \\
\hline Rhinocladiella aquaspersa ${ }^{\mathbf{P}}$ & 3 & 37,5 & 1 & 12,5 & 4 & 50,0 & - & - & 8 \\
\hline Rhizopus ozygosporus ${ }^{\mathbf{P}}$ & 5 & 41,7 & 4 & 33,4 & 2 & 16,6 & 1 & 8,3 & 12 \\
\hline Rhodotorula minuta ${ }^{\mathbf{P}}$ & 3 & 75,0 & - & - & 1 & 25,0 & - & - & 4 \\
\hline R. mucilaginosa ${ }^{\mathbf{P}}$ & 4 & 66,7 & - & - & 2 & 33,3 & - & - & 6 \\
\hline Stachybotrys chartarum ${ }^{\mathbf{P}}$ & 4 & 80,0 & - & - & 1 & 20,0 & - & - & 5 \\
\hline Syctalidium lignicola ${ }^{\mathbf{P}}$ & 2 & 100 & - & - & - & - & - & - & 2 \\
\hline Syncephalastrum racemosum ${ }^{\mathrm{NP}}$ & 3 & 37,5 & 1 & 12,5 & 4 & 50,0 & - & - & 8 \\
\hline Verticillium chlamydosporium $^{\mathbf{N P}}$ & 7 & 46,7 & 2 & 13,2 & 5 & 33,4 & 1 & 6,7 & 15 \\
\hline TOTAL & 400 & 30,6 & 372 & 28,5 & 318 & 24,4 & 215 & 16,5 & 1305 \\
\hline
\end{tabular}

P- pathogenic, NP- not pathogenic, T- toxigenic, A- allergenic 
Fig.1 Distribution of colony forming units (CFU) before and after cleaning of environments A and $\mathrm{B}$ at the Neonatal intensive care unit (ICU) in the hospital

Dr. Alberto Antunes (Maceió - Brazil)

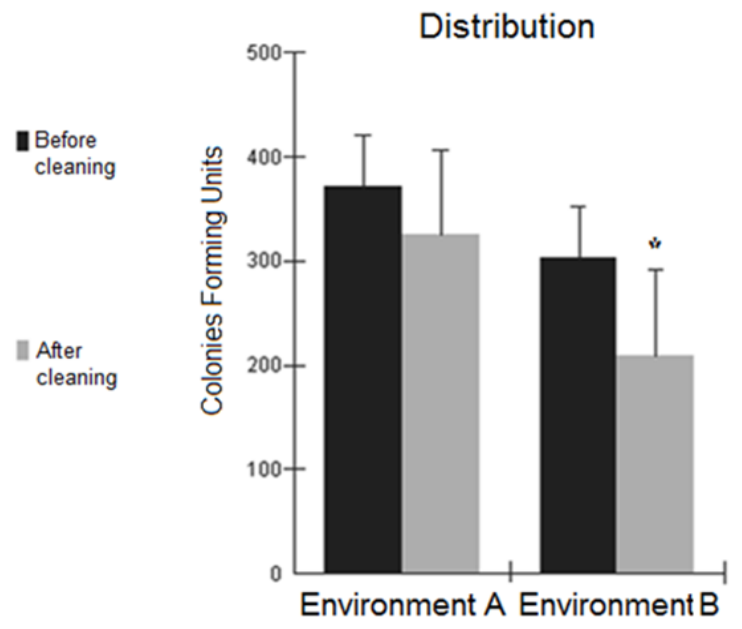

Fig.2 Distribution of colony forming units (CFU) of Cladosporium, Penicillium and Aspergillus species before and after cleaning of environments $\mathrm{A}$ and $\mathrm{B}$ at the neonatal intensive care unit (ICU) in the hospital Dr. Alberto Antunes (Maceió - Brazil)

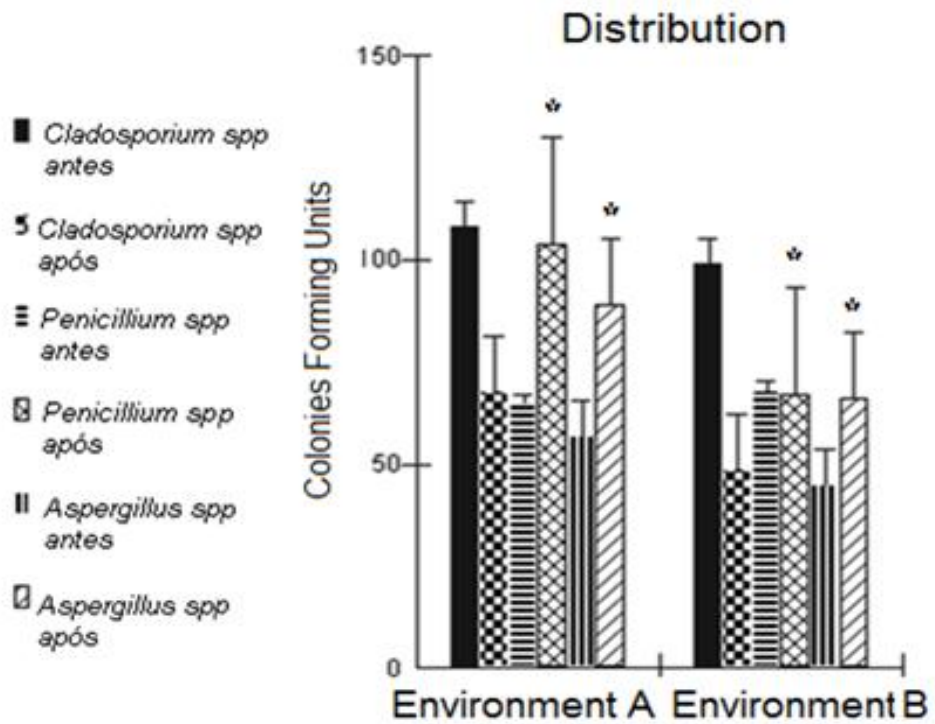


Fig.3 Fungi species isolated from the air conditioner filters of two environments from the neonatal ICU in the hospital Dr. Alberto Antunes (Maceió - Brazil)

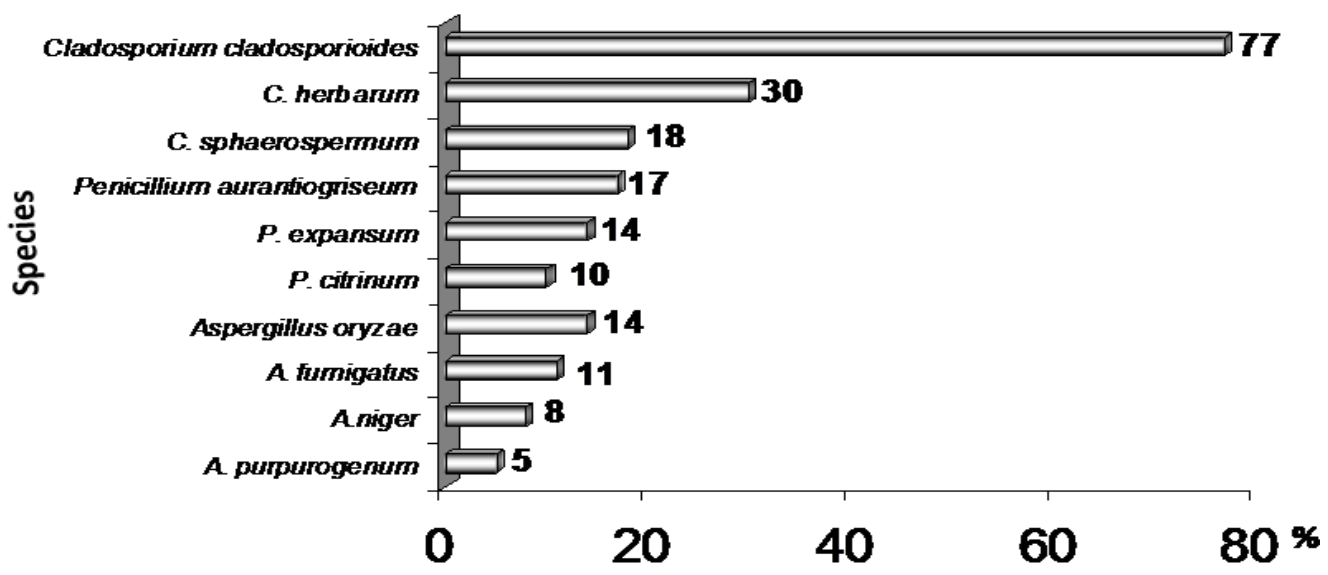

In Brazil, there are few data on the airborne fungi in hospital environments, especially those related to identification to species level.

The species $C$. cladosporioides was also found in $80 \%$ of isolates from air conditioners filters. However, Morbim and Salmito (2006) when evaluating the mycoflora from air conditioners in the ICU of Teresina - Brazil observed that Aspergillus niger was the most commonly species found in $60 \%$ of equipment, followed by Aspergillus fumigatus and Trichoderma koningii also present in this study in less frequency, with the exception of Trichoderma koningii that was not found in this study. The air conditioners in window, split or central concentrates microorganisms in the filters, evaporating unit and stagnant water from the pan. This fact associated with the cumulative phenomenon of $90 \%$ recycled air promotes increase in the number of microorganisms in order 1.000-100.000 times compared to the external environment (Lacerda, 2000). The air recirculation and the microorganisms are a hazard to individuals who remain for a long time inhaling the air, this may cause respiratory tract infections such as sinusitis, rhinitis, tonsillitis, pharyngitis, bronchitis, pneumonia, asthma, colds and flu. In this study, we report the presence of pathogenic, toxigenic and allergenic fungi in the air of two neonatal intensive care units. For one of the evaluated ICUs, the cleaning procedure was not sufficient to reduce airborne fungal concentration, which may be important when considering the immunological condition of patients present in this environment.

Among the filamentous fungi identified, $C$. cladosporioides, $P$. aurantiogriseum and $A$. oryzae were the most prevalent species in the analyzed environments. Regarding yeast fungi, Candida species such as $C$. parapsilosis, C. guilliermondii, C. tropicalis and $C$. albicans were present, demonstrating that indoor air may be an important risk factor for the spread of infection-related pathogens in neonates.

Completely eliminate the risk of health problems caused by fungi is practically impossible, but it can be reduced to a minimum standard level. Regular monitoring is essential for air control quality and for detecting the presence of hazardous microorganisms to human health and these data can be used to define specific indoor air quality guidelines at hospital environments.

The present study shows new results about fungi species found in the hospital environments of neonatal ICU in Brazil, 
providing a valuable tool for pathogens control and decrease in the level of infection in air-conditioning hospital environments.

\section{References}

Aboul-Nasr, M.B., Zohri, A.A. and Amer, E.M. 2014. Indoor Surveillance of Airborne Fungi Contaminating Intensive Care Units and Operation Rooms in Assiut University Hospitals, Egypt. Journal of Health Science., (2): 20-27.

Alexopouolos, C.J., MIMS, C.W. and Blackwell, M. 1996. Introductory Mycology. $4^{\text {th }}$ ed. New York, Jonh Wiley \& Sons.

Azimi, F., Naddafi, K., Nabizadeh, R., Hassanvand, M.S., Alimohammadi, M., Afhami, S. and Musavi, S.N. 2013. Fungal air quality in hospital rooms: a case study in Tehran, Iran. J Environ Health Sci. Eng., (1): 30, doi:10.1186/2052-336X-11-30.

Baxi, S. N., Portnoy, J. M., LarenasLinnemann, D., Phipatanakul, W., Barnes, C., Baxi, S., Levetin, E. 2016. Exposure and health effects of fungi on humans. The Journal of Allergy and Clinical Immunology: In Practice, 4(3), 396-404.

Boff, C., Zoppas, B.C., Aquino, V.R., Kuplich, N.M., Miron, D. and Pasqualotto, A.C. 2013. The indoor air as a potential determinant of the frequency of invasive aspergillosis in the intensive care. Mycoses., (5):527531.

Brasil, Resolução - RE nº 09.2003. Orientação Técnica revisada contendo Padrões da Qualidade do Ar Interior em ambientes climatizados artificialmente de uso público e coletivo. Diário Oficial da União, Brasília., Pp. 35-37.

Cabo Verde, S., Almeida, S.M., Matos, J.,
Guerreiro, D., Meneses, M., Faria, T., Botelho, D., Santos, M. and Viegas, C. 2015. Microbiological assessment of indoor air quality at different hospital sites. Research in Microbiology., 7: 557-63.

Chang, C.Y., Tseng, L. and Yang, L.S. 2015. Microbial Air Contamination in An Intensive Care Unit. International Journal of Public Health Science., Volume 4, Number 3, pp. 145-151.

Cristina, M.L., Sartini, M. and Spagnolo, A.M. 2009. Health care-acquired aspergillosis and air conditioning systems. J Prev Med Hyg., 50: 3-8.

Duarte, J.L.M.B. and Mendonca, G.A.S. 2005. Avaliação dos óbitos neonatais em recém-nascidos de muito baixo peso em quatro maternidades no Município do Rio de Janeiro, Brasil.Cad. Saúde Pública., 21: 102-121.

Gebel, J., Exner, M., French, G., Chartier, Y., Christiansen, B., Gemein, S., GoroncyBermes, P., Hartemann, P., Heudorf, U., Kramer, A., Maillard, J.Y., Oltmanns, P., Rotter, M. and Sonntag, H.G. 2013. The role of surface disinfection in infection prevention. GMS Hygiene and Infection Control., 8(1): doi: 10.3205/dgkh000210.

Gonçalves, C.L., Mota, F.V., Ferreira, G.F., Mendes, J.F., Pereira, E.C., Freitas, C.H., Vieira, J.N., Villareal, J.P. and Nascente, P.S. 2017. Airborne fungi in an intensive care unit. Braz. J. Biol., Epub July 27: https://dx.doi.org/10.1590/15196984.06016.

Hoog, G.S., Guarro, J., Gené, J. and Figueras, M.J. 2000. Atlas of clinical fungi, $2^{\mathrm{a}} \mathrm{ed}$ CBS, Spain. 2000. 1126pp.

Lacerda, R.A. 2000. Centro cirúrgico. In: Fernandes ATF. et al., Infecção Hospitalar e suas Interfaces na Área da Saúde, 1st ed. São Paulo: Editora Atheneu. p. 1307-1322. 
Lugauskas, A. and Krikstaponis, A. 2004. Filamentous fungi isolated in hospitals and same medical institutions in Lithuania. Indoor and Built Environ.13: 101-108.

Morbim, M. and Salmito, A.M. 2006. Microbiota fúngica dos condicionadores de ar nas unidades de terapia intensiva de Teresina, PI.Rev. Soc. Bras. Med. Trop., 39: 556-559.

Napoli, C., Marcotrigiano, V. and Montagna, M.T. 2012. Air sampling procedures to evaluate microbial contamination: a comparison between active and passive methods in operating theatres. $B M C$ Public Health., 12: 594.

Nascimento, J. P. M., López, A. M. Q., Andrade, M., Araujo, L. A., Filho, E. A. S. 2019. Airborne Fungi in Indoor Hospital Environments. Int. J. Curr. Microbiol. App. Sci, 8(1), 2749-2772.

Nevalainen, A., Täubel, M. and Hyvärinen, A. 2015. Indoor fungi: Companions and contaminants. Indoor Air., Volume 25, number 2, pp. 125-156.

Okten, S. and Asan, A. 2012. Airborne fungi and bacteria in indoor and outdoor environment of the Pediatric Unit of Edirne Government Hospital. Environ Monit Assess., 184: 1739-1751.

Rangaswamy, B.E., Francis, F., Prakash, K.K. and Manjunath, N.S. 2013. Variability in airborne bacterial and fungal population in the tertiary health care centre. Aerobiologia., 29: 473-479.

Riddel, R.W. 1950. Permanent stained by ecological preparations obtained by slide culture. Mycology., 42: 265-270.

Rocha, C.A., Báez, N.A., Villarroel, E.V. and Quintero, G.M. 2012. Study of Bioaerosols in Surgical Theaters and Intensive Care Units from a Public General Hospital. The Journal of Bioscience and Medicine, Volume 2, Number 3, doi: 10.5780/jbm2012.26.

Rostami, N., Alidadi, H., Zarrinfar, H. and Salehi, P. 2017. Assessment of indoor and outdoor airborne fungi in an Educational, Research and Treatment Center. Italian Journal of Medicine., 11: 52-56.

Sepahvand, A., Azimi, F., Hashemi, S.Y., Rashidi, R., Safari, M. and Zeidali, S. 2017. General hospitals indoor air quality in Lorestan, Iran. Journal of Air Pollution and Health., 2(1): 51-56.

Setlhare, G., Malebo, N., Shale, K. and Lues, R. 2014. Identification of airborne microbiota in selected areas in a health-care setting in South Africa. BMC Microbiology., 14: 100, doi: 10.1186/1471-2180-14-100.

Sherf, A.F. 1943. A method for maintaing Phytomonas sepedonica in culture for long periods without transfer. Phytopathology., 33: 330-332.

Tong, X., Xu, H., Zou, L., Cai, M., Xu, X., Zhao, Z., Xiao, F. and Li, Y. 2017. High diversity of airborne fungi in the hospital environment as revealed by meta-sequencing-based microbiome analysis. Sci. Rep., 7: 39606.

\section{How to cite this article:}

Aryanna Kelly Pinheiro Souza, Jean Phellipe Marques do Nascimento, Maria Anilda dos Santos Araújo, Krystianelly Patrícia da Silva Pedrosa, Bruno Mendes Tenorio, Luana Luzia Santos Pires, Gabryelle Barbosa Cordeiro de Lima, Rebeca Ingrid dos Santos Barboza and Eurípedes Alves da Silva Filho. 2019. Airborne Fungi in Neonatal Intensive Care Unit of a Public Hospital in Brazil. Int.J.Curr.Microbiol.App.Sci. 8(12): 1210-1219.

doi: https://doi.org/10.20546/ijcmas.2019.812.149 